general. Dr Sen, who is 69 , has not yet decided whether to stand again this year for election to the office which he has held since 1956. Although a previous ruling excludes the renewal of his term, this could doubtless be circumvented if Dr Sen were willing to stand and could find enough support. Two other names have been put forward for the job-Mr H. Boerma, ExecutiveDirector of the UN-FAO world food programme, and Dr Hernan Santa Cruz, until recently FAO Assistant Director for Latin America. Much will depend on how delegates feel about the record of the FAO in the past ten years; if there is much criticism, a candidate who has had no previous contact with the organization may stand the best chance. By general agreement, the World Development Decade was a disastrous failure; now hopes-such as they are-are based on the second development decade.

\section{Libraries in Britain}

THE principal recommendation of the Committee on Libraries set up by the University Grants Committee is that a British National Library should be established, based on the British Museum. The committee was clearly disturbed that Britain differs from the United States and the Soviet Union in having no "true apex" to the library system. The result, it says, is that many of the functions associated with national libraries are shared among other organizations, not all of which are adequately equipped to undertake them. These functions include maintaining the central collection of the nation's literature, full coverage of for'eign literature, publication of the national bibliography and national catalogues, and acting as a centre of interlibrary lending. Both Wales and Scotland do have national libraries, but the report says that they have insufficient money available for important purchases.

The report makes a large number of recommenda. tions, somewhat miscellaneously put together. Students are taken to task for not spending enough of their grants on books, but instead preferring to borrow them from university libraries or public libraries. The committee attributes this to waywardness rather than poverty, and recommends that students should be given book grants in the form of vouchers which can only be used for buying books. This suggestion would have the effect of switching the burden of book buying from the UGC to the local education authorities, and the same trend is evident in a suggestion that student unions should provide their own libraries out of funds derived from local education authorities.

The National Lending Library for Science and Technology should continue to lend medical, scientific and technological literature, and a national plan should be devised for providing social science literature, taking into account the fact that the NLL itself will soon be able to make some contribution in this field. The National Central Library, on the other hand, should be absorbed into the National Library, together with the libraries which benefit from legal deposit-the British Museum, Oxford and Cambridge. Stacks should be accessible to all readers, and seminar rooms provided in research libraries. Staff should be increased, better trained and better paid. To pay for all this, recurrent grants to libraries should be increased-the report says that the new universities and colleges of advanced technology have not yet been able to create libraries of university standard-and to administer it, a special UGC sub-committee should be set up.

\section{Reappraisal for Chemistry}

Chemistry teaching in Britain is once again under analysis. A survey by a Royal Society committee under Professor R. A. Raphael was reported last week (Nature, 214, 960; 1967) and it now emerges that the Royal Institute of Chemistry is conducting an examination on its own account. With luck, it should fill the gaps left by the Royal Society committee.

Professor C. Eaborn of the University of Sussex is chairman of the institute's committee of 12 , which includes a full time statistician and an industrial psychologist. The survey was started by a series of group discussions with various categories of chemist -including undergraduates, postgraduates, university teachers and industrialists - in order to set the scene for the survey. The discussions were intended to discover what people actually say about chemistry courses in British universities, and to avoid the possibility that the survey will be vitiated by the preconceptions of the people conducting it. The group discussions will be followed by individual discussions on a semi-formal basis and ultimately by questionnaires. These have already gone out to undergraduates, so as to catch them before the summer vacation, and will also be sent out to groups of 500 in each of the seven categories being considered.

On the industrial front, the survey will cover graduates who have been in industry only a few years, as well as older men in managerial positions. The questions will try to discover why people choose chemistry, how valuable existing courses are, and whether anything should be done to improve them. Appointments boards, often a forgotten link in the chain, will also be asked for their views. When the survey is finished, it is hoped that it may influence the re-shaping of chemistry courses for the seventies.

\section{Activation Analysis}

\section{from a Correspondent}

THE impact of nuclear technology on the life sciences is still dominated by experiments with radioactive tracers, but many novel and potentially useful developments based on activation analysis were described or proposed at a symposium held in Amsterdam from May 8-12 under the auspices of the International Atomic Energy Agency.

In labelling a large biological system with a radioactive tracer, it is sometimes difficult to obtain an adequate specific activity while conforming to the requirements of radiation safety applicable to the experimenter and the environment. The propagation of pollen, a matter of great concern in plant breeding, may be studied by radioactive tracer techniques, but the amount of activity required for labelling (J-2 curies of phosphorus-32 for an adult pine tree) is inconveniently large. Recent studies in Germany have shown that manganese, injected into the tree as sulphate, is suitable as a stable tracer. Pollen grains are collected on polycthylene foils (distributed in the crowns of neighbouring trees) which are then irradiated with thermal neutrons. The labelled pollen grains are identified and counted by autoradiography. 